\title{
IMPLEMENTASI METODE MARKER BASED TRACKING PADA AUGMENTED REALITY SEBAGAI MEDIA PEMBELAJARAN RUMAH ADAT TRADISIONAL (STUDI KASUS : SD NEGERI SINDANGJAYA CIANJUR)
}

\author{
Tarsinah Sumarni ${ }^{1,}$ Sri Erina Damayanti ${ }^{2}$ Haris Saputra ${ }^{3}$ \\ Program Studi Teknik Informatika ${ }^{1,2,3}$ \\ Sekolah Tinggi Teknologi Bandung ${ }^{1,2,3}$ \\ tarsinahsumarni@ sttbandung.ac.id ${ }^{1}$, srierina@sttbandung.ac.id², harislvd8@gmail.com
}

\begin{abstract}
Abstrak
Rumah adat tradisional adalah rumah yang memiliki ciri khas tertentu yang memiliki keunikan tersendiri dan melambangkan budaya adat lokal setempat. Rumah adat khususnya yang berada di pulau jawa yang tersebar di berbagai provinsi seperti provinsi Banten, provinsi Jakarta, provinsi Jawa Barat, provinsi Jawa Tengah, provinsi Jawa Timur, dan provinsi Yogyakarta juga memiliki rumah adat masing-masing di berbagai tempat yang tersebar di pulau jawa. Menampilkan 3D objek rumah adat dengan teknologi Augmented reality dan menggunakan Marker sebagai penanda khusus, akan menjadi pengalaman pembelajaran rumah adat yang sangat menyenangkan bagi siswa siswi SD Negeri Sindangjaya, dengan aplikasi yang bisa dijalankan di sistem operasi android. Aplikasi ARRA PPJ merupakan aplikasi yang mampu menampilkan 3D objek rumah adat dari 6 provinsi dan mampu menampilkan 16 3D objek rumah adat yang berada di provinsi yang tersebar di pulau Jawa, yang menggunakan teknologi Augmented reality. Augmented reality ialah teknologi yang menggabungkan dunia virtual kedalam dunia nyata yang dimana pengguna dapat berinteraksi dengan konten visual di dunia nyata. Buku-buku yang menjadi acuan dalam media pembelajaran memiliki kekurangan terbatasnya tampilan rumah adat secara visual, penerapan teknologi Augmented reality pada media pembelajaran rumah adat yang bertujuan untuk memberikan informasi-informasi menegenai rumah adat yang ditampilkan seperti bangunan rumah adat, sejarah singkat, nama-nama rumah adat, rumah adat berasal dari Provinsi mana.
\end{abstract}

Kata Kunci : Rumah adat, Pembelajaran, Augmented reality, Pulau Jawa, Provinsi.

\begin{abstract}
The traditional house is a house that has certain characteristics that have its own uniqueness and symbolizes the local traditional culture. Traditional house, especially those on the island of java, which are scattered in various provinces such as Banten province, Jakarta province, Central Java province, East Java province, and Yogyakarta province also have their own traditional houses in various places spread across the island of Java. Displaying 3D traditional house objects with Augmented reality technology and use Marker as special Marker, will be a very fun traditional house learning experience for students of SD Negeri Sindangjaya, with application that can run on the Android operating system. The ARRA PPJ application is an application that is able to display $3 D$ tradisional house objects from 6 provinces and is able to display $163 D$ traditional houses objects across Java, used Augmented reality technology. Augmented reality is a technology that combined the virtual word into the life which are users can interact with visual content in real life. Books that are used as references in learning media have the lack of limited visual appearance of traditional houses, the application of Augmented reality technology to tradisional house learning media which aims ti give information about tradisional houses displayid such as traditional house buildings, short history, names of traditional house the traditional houses comes from which province.

Keywords : Traditional house, Learning, Augmented reality, Java Island, Province.
\end{abstract}

\section{PENDAHULUAN}

Perkembangan teknologi diera modern seperti sekarang ini terutama dalam teknologi informasi khususnya pemprosesan citra gambar digital telah berada pada tahap yang sangat baik. Dimana penerapan Implementasi pemrosesan gambar digital saat ini telah merambah pada beberapa Implementasi, salah satunya ialah Augmented reality. Augmented reality adalah teknologi yang menggabungkan realita dua dimensi, tiga dimensi dan lalu memproyeksikan benda-benda maya tersebut kedalam waktu nyata dan lingkungan nyata.

Objek virtual dapat berupa teks, animasi, model 3D atau video yang digabungkan dengan lingkungan nyata sehingga pengguna dapat merasakan sensasi Objek virtual di lingkungannya.

Rumah adat merupakan peninggalan budaya jaman dulu yang memiliki ciri khas bangunan tertentu disuatu tempat atau daerah di Indonesia, yang menggambarkan budaya dan ciri khas masyarakat setempat. Rumah adat tradisional pada umumnya memiliki ukiran-ukiran indah yang menjadi ciri khas adat lokal setempat. SD Negeri Sindangjaya adalah tempat pendidikan sekolah dasar negeri yang berdiri dari tahun 1975 yang berada di Desa Cikondang Kecamatan Bojongpicung kabupaten Cianjur, saat ini ditahun 2021 SD Negeri Sindangjaya memiliki siswa sebanyak 161 siswa.

Pemahaman siswa akan budaya Rumah Adat tradisional yang telah disampaikan oleh guru, ketika guru menjelaskan budaya rumah adat dengan tidak adanya Objek gambar yang ditampilkan atau berupa text yang dijelaskan. Dari hal itu maka pemahaman siswa akan kurang memahami pelajaran tersebut.

Dengan adanya Objek gambar yang ditampilkan, siswa siswi SD Negeri Sindangjaya diharapkan dapat memahami budaya Rumah Adat tersebut. Untuk menampilkan bangunan rumah adat tradisional kepada siswa siswi SD Negeri Sindangjaya dengan tampilan 3D sebagai media pengenalan dan pembelajaran dengan mengunakan Augmented reality. 
Dengan teknologi Augmented reality yang bertujuan menampilkan informasi di layar Smartphone yang memberikan informasi terkait bangunan rumah adat, sejarah singkat, menampilkan bangunan rumah adat dengan tampilan 3D, namanama rumah adat.

Diharapkan dengan adanya aplikasi ini siswa siswi SD Negeri Sindangjaya mendapatkan pengetahuan bentuk dari bangunan rumah adat tersebut dengan tampilan 3D dan Siswa siswi SD Negeri Sindangjaya mendapatkan informasi lengkap terkait rumah adat di Provinsi yang berada dipulau jawa. Identifikasi pengenalan gambar melalui kamera Smartphone yang diarahkan pada Marker dikenali sebagai Marker based tracking. Marker based tracking inilah yang berfungsi untuk menampilkan 3D model pada layar Smartphone.

\section{TINJAUAN PUSTAKA}

\section{Rumah adat}

Indonesia adalah negara kepulauan dari sabang sampai merauke yang terdiri atas berbagai adat, budaya dan suku bangsa. Setiap suku bangsa memiliki adat dan budaya nya masing-masing, bahasa, seni tari, pakaian adat, hingga rumah adat. Perbedaan tersebut menunjukkan bahwa Indonesia adalah negara yang kaya akan budayabudayanya. Secara wilayah administratif, Indonesia terbagi menjadi 34 provinsi. Namun, dalam satu provinsi sesungguhnya tidak dihuni oleh satu suku saja, Di setiap provinsi bisa terdapat lebih dari satu rumah adat [1].

2. Implementasi

Implementasi ialah suatu proses mendapatkan suatu hasil yang sesuai dengan tujuan atau sasaran kebijakan itu sendiri, dimana pelaksana kebijakan ialah melakukan suatu aktivitas atau kegiatan [2].

3. Augmented reality

Augmented reality tidak lain ialah informasi digital yang terletak diatas Objek dunia nyata yang dimana pengguna dapat beriteraksi dengan konten virtual atau maya didunia nyata yang dapat membedakan antara dunia nyata, maya dan virtual [3].

4. $\quad$ Marker based tracking

Marker based tracking merupakan metode Augmented reality yang mengidentifikasi Marker dan pola dari Marker tersebut untuk menambahkan atau menampilkan suatu Objek 3D virtual ke lingkungan yang nyata. Marker merupakan ilustrasi persegi hitam dan putih dengan sisi hitam tebal dengan pola hitam ditengah persegi dan latar belakang berwarna putih. Komputer akan dapat mengenali posisi dan orientasi Marker tersebut dan menciptakan dunia virtual 3D yaitu titik $(0,0,0)$ dan 3 sumbu yaitu X, Y, dan Z. Marker based tracking ini sudah sangat lama dikembangkan sejak 1980-an dan pada awal 1990-an mulai dikembangkan untuk penggunaan teknologi Augmented reality [4].

5. Multimedia

Multimedia juga bisa berarti kombinasi dari paling sedikit dua media input atau output, multimedia pun bisa dibagi menjadi dua kategori yaitu, Multimedia linier dan Multimedia interaktif. Multimedia linier adalah Multimedia yang tidak dilengkapi dengan alat pengontrol yang dapat dioperasikan langsung oleh pengguna. Multimedia pembelajaran dapat diartikan sebagai aplikasi Multimedia yang digunakan dalam proses pembelajaran, dan juga untuk menyalurkan pesan (pengetahuan, sikap dan keterampilan) serta dapat merangsang pikiran, perasaan, perhatian dan kemauan yang belajar sehingga secara sengaja proses belajar terjadi, bertujuan, terarah, dan terkendali [5].

\section{Extreme Programming}

Extreme Programming (XP) merupakan salah satu metode pengembangan sistem yang tangkas paling banyak digunakan dan menjadi pendekatan yang sangat terkenal. Tujuan Extreme Programming (XP) adalah tim yang terbentuk tidak harus tim yang besar antara berukuran kecil hingga menengah, tidak perlu menggunakan tim besar. Hal ini dimaksudkan untuk mengatasi persyaratan yang tidak jelas dan perubahan persyaratan pada saat pengembangan dengan sangat cepat [6].

\section{ANALISIS DAN PERANCANGAN}

Penelitian ini metode pengembangan Extreme Programming. Ada beberapa tahapan pada metode pengembangan XP, seperti yang dapat kita lihat pada gambar 1 . 
1. Planning

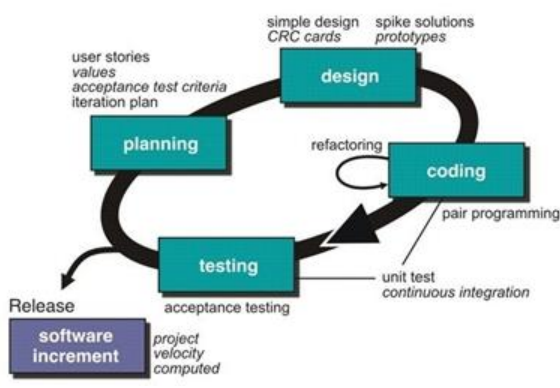

Gambar 1 Tahapan Extreme Programming

Tahap planning aktivitas perencanaan dalam penelitian ini dimulai dari analisis sistem yang sedang berjalan dan analisis sistem yang dibutuhkan.

2. Design

Tahap design memberikan gambaran terhadap sistem yang akan dibangun atau dikembangkan serta untuk memahami alur informasi dan proses yang ada didalam sistem. Berikut merupakan tahapan yang akan dilakukan dalam perancangan sistem. Pada tahapan ini ada beberapa komponen - komponen yang dibutuhkan. Pemodelan sistem yang digunakan yaitu :

a. Unifiled Modelling Language (UML)

Beberapa pemodelan yang digunakan untuk membangun sistem, dapat dilihat seperti yang terlihat pada gambar 2.

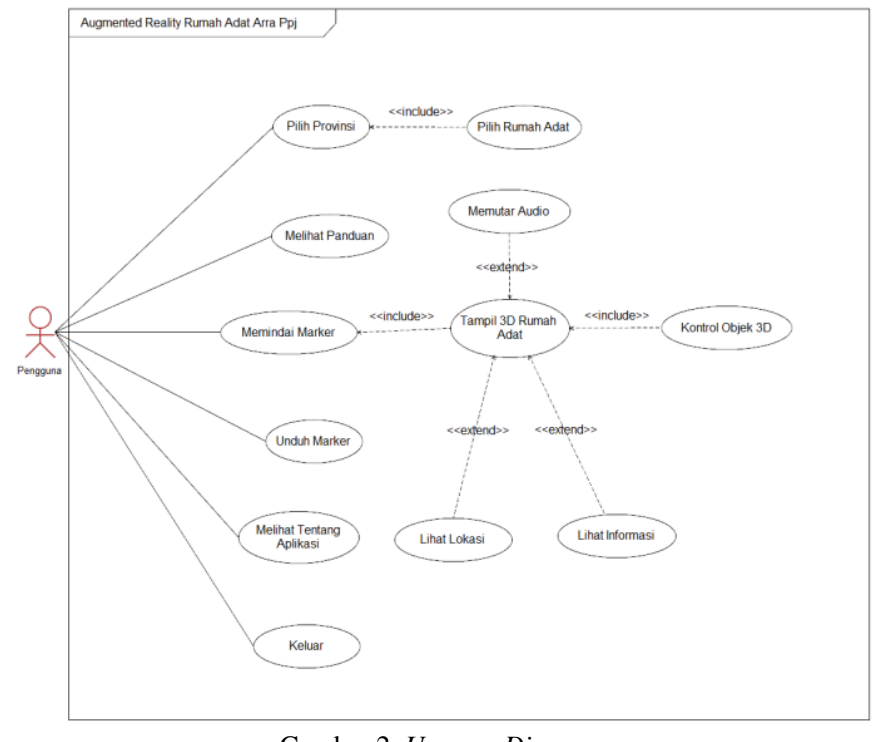

b. Perancangan Antarmuka

Pada tampilan interface beberapa menu dalam aplikasi, dapat dilihat seperti yang terlihat pada gambar 3.

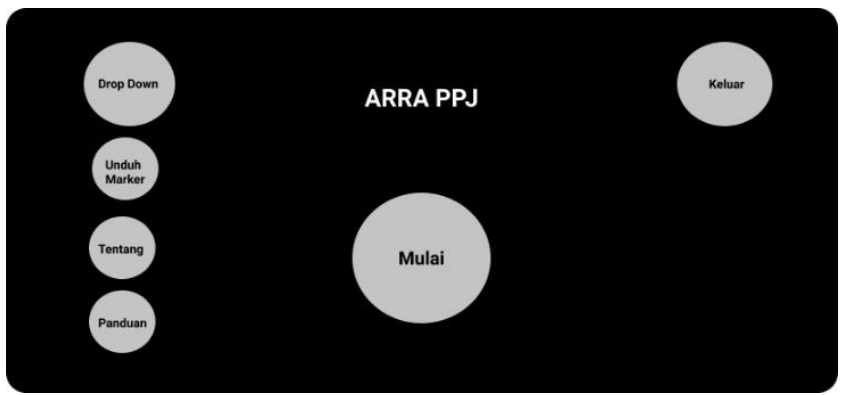

Gambar 3 Home 


\section{Coding (Pengkodean)}

Tahap berikutnya adalah coding atau pengkodean dimana implementasi dari perancangan model sistem yang telah dibuat kedalam bentuk user interface dengan menggunakan bahasa pemrograman C\# dan Unity sebagai Game Engine nya.

\section{4. $\quad$ Testing}

Pengujian aplikasi yang sudah dibangun menggunakan metode alpa testing yang dilakukan oleh penulis, yaitu menggunakan pengujian black box untuk pengujian semua tombol yang ada pada aplikasi dan pengujian beta testing, yaitu menggunakan kuesioner yang dibagikan kepada guru dan siswa SD Negeri Sindangjaya.

\section{IMPLEMENTASI SISTEM}

Pada bab ini akan menjelaskan tentang implementasi dari perancangan yang telah dibuat sebelumnya. Serta melakukan pengujian untuk mengetahui apakah aplikasi yang sudah dibuat sudah sesuai dengan apa yang diharapkan sebelumnya. Berikut adalah desain untuk perancangan yang telah direncakan dan dituangkan ke dalam bahasa pemrograman $\mathrm{C \#}$ sehingga menghasilkan aplikasi yang sesuai.

1. Tampilan Aplikasi

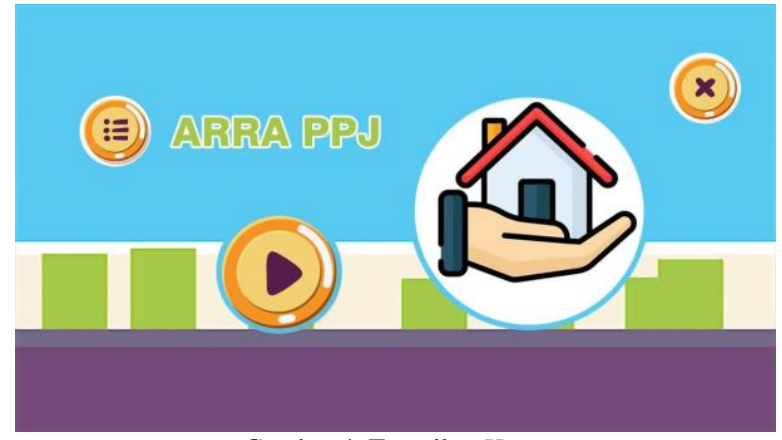

Gambar 4. Tampilan Home

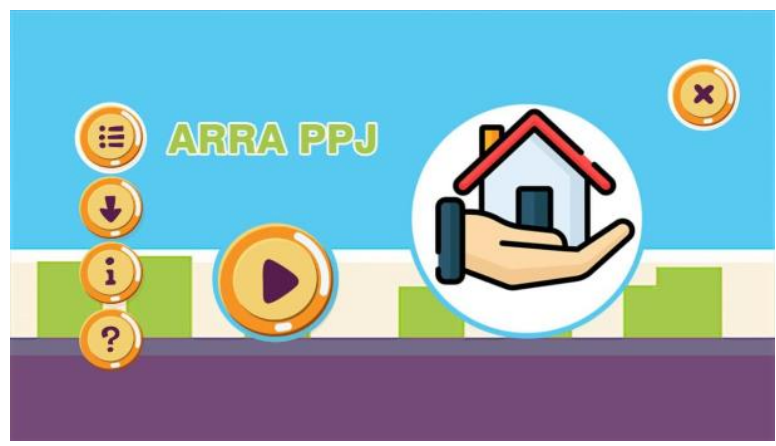

Gambar 5. Menu DropDown

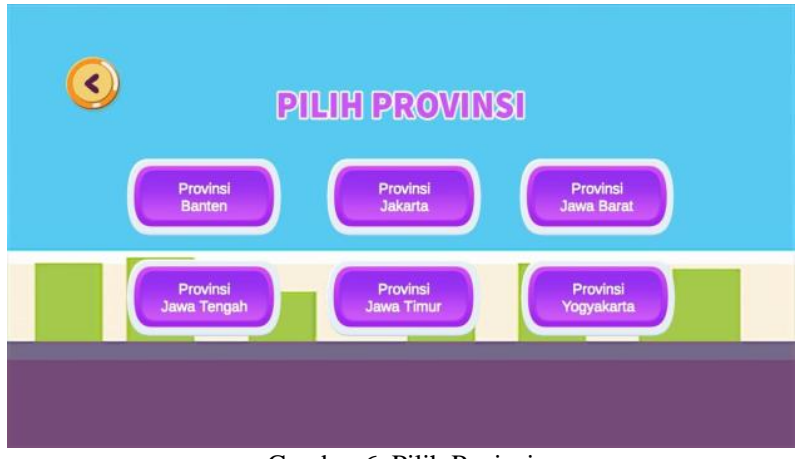

Gambar 6. Pilih Povinsi 


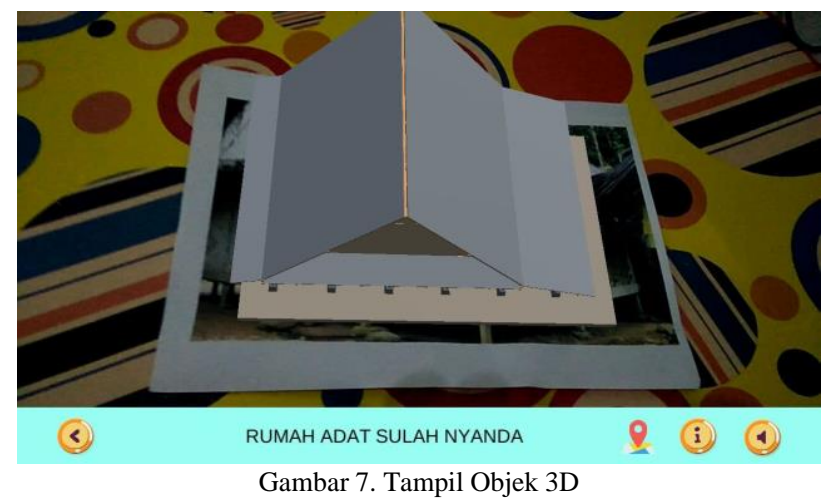

\section{KESIMPULAN}

Berdasarkan dari hasil penelitian yang telah dilakukan, maka ada beberapa kesimpulan yang dapat disampaikan:

1. Aplikasi yang dibuat dapat membantu guru dalam menjelaskan materi budaya rumah adat tradisional.

2. Aplikasi yang dibuat dapat menyampaikan informasi Rumah Adat kepada siswa siswi SD Negeri Sindangjaya dengan disertai lokasi Provinsinya.

\section{REFERENSI}

[1] Poerwaningtias I, Suwarto NK. Rumah adat Nusantara [Internet]. Kementerian Pendidikan dan Kebudayaan; 2017 [cited 2021 Sep 4]. 56 p. Tersedia dari: https://b-ok.asia/book/11308388/da7960

[2] Dedi Irawan M, Simargolang SA. Implementasi E-Arsip Pada Program Studi Teknik Informatika. J Teknol Inf [Internet]. 2018 Jun 7 [cited 2021 Feb 8];2(1):67-84. Tersedia dari: http://www.jurnal.una.ac.id/index.php/jurti/article/view/411

[3] Danang Aji Pangestu, Iskandar Fitri, Fauziah. AUGMENTED REALITY SEBAGAI MEDIA PENGENALAN DAN PROMOSI UNIVERSITAS NASIONAL. (Jurnal Teknol Informasi) Vol4, No1, Juni 2020 [Internet]. 2020;(Jurnal Te((Jurnal Teknol. Informasi) Vol.4, No.1, Juni 2020):8. Tersedia dari: http://jurnal.una.ac.id/index.php/jurti/article/view/1230

[4] Abdulghani T, Sati BP. Pengenalan Rumah Adat Indonesia Menggunakan Teknologi Augmented Reality Dengan Metode Marker Based Tracking Sebagai Media Pembelajaran. Media J Inform [Internet]. 2019 Mar 7 [cited 2021 Feb 8];11(1):43-50. Tersedia dari: http://jurnal.unsur.ac.id/mjinformatika

[5] Rawis ZC, Tulenan V, Sugiarso BA. Penerapan Augmented Reality Berbasis Android Untuk Mengenalkan Pakaian Adat Tountemboan. J Tek Inform [Internet]. 2018 Feb 26 [cited 2021 Feb 8];13(1). Tersedia dari: https://ejournal.unsrat.ac.id/index.php/informatika/article/view/20190

[6] Supriyatna A. METODE EXTREME PROGRAMMING PADA PEMBANGUNAN WEB APLIKASI SELEKSI PESERTA PELATIHAN

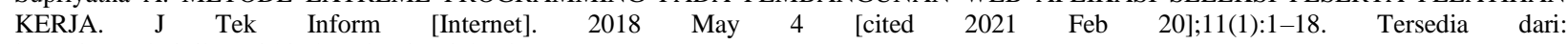
http://journal.uinjkt.ac.id/index.php/ti/article/view/6628 